\title{
The use of personal health information
} outside the circle of care: consent preferences of patients from an academic health care institution

\author{
Sarah Tosoni ${ }^{1}$, Indu Voruganti ${ }^{1,2}$, Katherine Lajkosz ${ }^{3}$, Flavio Habal ${ }^{4}$, Patricia Murphy ${ }^{5}$, Rebecca K. S. Wong ${ }^{1,2,6}$,
} Donald Willison ${ }^{6}$, Carl Virtanen ${ }^{7}$, Ann Heesters ${ }^{8,9}$ and Fei-Fei Liu ${ }^{1,2,10^{*}}$

\begin{abstract}
Background: Immense volumes of personal health information (PHI) are required to realize the anticipated benefits of artificial intelligence in clinical medicine. To maintain public trust in medical research, consent policies must evolve to reflect contemporary patient preferences.

Methods: Patients were invited to complete a 27-item survey focusing on: (a) broad versus specific consent; (b) optin versus opt-out approaches; (c) comfort level sharing with different recipients; (d) attitudes towards commercialization; and (e) options to track PHI use and study results.

Results: 222 participants were included in the analysis; 83\% were comfortable sharing PHI with researchers at their own hospital, although younger patients ( $\leq 49$ years) were more uncomfortable than older patients $(50+$ years; $13 \%$ versus $2 \%$ uncomfortable, $p<0.05$ ). While $56 \%$ of patients preferred broad consent, $38 \%$ preferred specific consent; $6 \%$ preferred not sharing at all. The majority of patients (63\%) preferred to be asked for permission before entry into a contact pool. Again, this trend was more pronounced for younger patients ( $\leq 49$ years: $76 \%$ ). Approximately half of patients were uncomfortable sharing PHI with commercial enterprises (51\% uncomfortable, 27\% comfortable, 22\% neutral). Most patients preferred to track PHI usage (61\%), with the highest proportion once again reported by the youngest patients ( $\leq 49$ years: $71 \%$ ). A majority of patients also wished to be notified regarding study results (70\%).

Conclusions: While most patients were willing to share their $\mathrm{PHI}$ with researchers within their own institution, many preferred a transparent and reciprocal consent process. These data also suggest a generational shift, wherein younger patients preferred more specific consent options. Modernizing consent policies to reflect increased autonomy is crucial in fostering sustained public engagement with medical research.
\end{abstract}

Keywords: Patient consent preferences, Data sharing, Consent policies

*Correspondence: Fei-Fei.Liu@rmp.uhn.ca

${ }^{10}$ Princess Margaret Cancer Centre, Department of Radiation Oncology,

700 University Avenue, Toronto, ON M5G 2M9, Canada

Full list of author information is available at the end of the article

\section{Background}

Rapid advancements in machine learning and artificial intelligence (AI) have generated a pressing need for massive volumes of personal health information (PHI). In an effort to capitalize on these technologies for medical discovery and innovation, some health organizations have encountered high-profile public scrutiny and/or legal 
action for sharing even de-identified health information outside the circle of care, with patients contesting claims that they actually provided informed consent, and questioning whether de-identification is truly possible $[1,2]$. Furthermore, patients are becoming aware of potentially controversial PHI uses (e.g. for gene editing, and some AI applications), and some are noting the increasing monetary value of $\mathrm{PHI}$ (e.g. to commercial companies) [3-5].

Indeed, the use of PHI for research without explicit consent is occurring $[3,6]$, leading some health law experts to raise the concern that consent issues are poised to become a major social controversy $[4,7]$. While some provisions in law permit the use of de-identified PHI for research without explicit consent, previous studies report that many patients do not distinguish between identifiable versus de-identified or anonymized data, and that they wish to be asked for consent even when PHI is de-identified $[8,9]$. Proper informed consent is the foundation upon which trusting relationships are built; a wellrecognized principle in health law, and prominent feature of international codes of ethics including the Declaration of Helsinki and the Nuremburg Code [10-13]. Beyond institutional privacy obligations, the duty of physicians to protect the privacy of their patients is sacrosanct, enshrined in normative documents including the Hippocratic Oath and professional codes of ethics [14]. While advocates for non-consensual access to PHI for research do exist, many scholars have been unequivocal that further public engagement is crucial to ensure the use of PHI is ethically defensible and patient-centered $[4,9,10$, 15-17].

Patient preferences for consent have been empirically studied for upwards of two decades, illuminating a diverse array of needs and views. In a large-scale European study, $61 \%$ of participants were concerned over third party access to $\mathrm{PHI}$; participants were strongly averse to sharing with health insurance and private pharmaceutical companies [18]. In studies by Willison and by Joly, Canadian patients also expressed significant concern over commercial uses of PHI $[9,15,19]$; with $57 \%$ indicating that de-identified PHI should not be used at all for marketing/commercial purposes [15]. Multiple studies also report that substantial majorities of patients wish to be consulted before their de-identified PHI is used for research purposes [16, 20, 21], even after being fully informed of the potential drawbacks such as less research being conducted [14]. Furthermore, many patients desired more specific options beyond one-time broad consent [16, 22-24]; in a comprehensive systematic review "the most notable finding is that many people do not favor broad consent for either research itself or for research and subsequent wide data sharing [24]." Taken together, these reports illuminate a consistent trend that if PHI is to be used outside one's own care, the opportunity for information control is considered an important element of respect for persons $[8,15]$.

While these studies have amplified patient voices within medical literature, policy changes have lagged, resulting in an unfortunate chasm between knowledge and practice. Indeed, previous studies have noted that healthcare organizations have a pervasive tendency to disregard mounting evidence that patients desire more information and control $[3,25,26]$. Therefore, the purpose of the current study was to acquire an in-depth understanding of the contemporary and specific consent needs of cancer patients at a large academic hospital to inform its own institutional consent policies.

\section{Methods}

Participants and procedure

A clinical research coordinator (CRC) invited patients in the waiting rooms of five radiation oncology clinics (breast, prostate, lung, thyroid, palliative) to complete a 10-min iPad survey ("Appendix 1") from January to December, 2019. Full Research Ethics Board (REB) approval was granted from the University Health Network (UHN). The only inclusion criterion was being a patient at the cancer centre, and consent was provided verbally. Completed surveys were stored separately, not linked to patients' names or medical records.

\section{Survey}

An original 27-item survey was developed specifically for this study, and comprised of four sections of multiple choice and 5-point Likert-scale questions. The survey was designed in consultation with a diverse array of experts from medicine, digital technology, bioethics, and public health policy. It was reviewed in-person with three patient partners to ensure readability and clarity. The welcome message was vital to protect the integrity of responses from a health literacy perspective ("Appendix 1"); we could not assume that all patients would be aware that their PHI holds value outside their own care and is sought-after by external sources. Five sections followed; Section 1: Asking for your Consent to Share; 2: Recipients; 3: Commercialization; 4: Tracking Sharing $\mathcal{E}$ Results; and 5: Background Questions.

\section{Sample size justification}

As a proof-of-concept survey study, sample size was chosen by convenience, hence statistical power calculation was not necessary. Our targeted sample size of 50 participants within each disease site would provide a confidence 
interval range of the preference rate (95\% CI: 0.36-0.64) as 0.28 with high accuracy.

\section{Statistical analysis}

Patient demographics were summarized using descriptive statistics. Distribution of responses to study questions were summarized using frequencies and percentages. Missing responses were not included in the denominator when calculating percentages. Results were also stratified by demographics to assess differences between groups, and the Chi-square test was utilized post-hoc to identify statistically significant differences between groups. Clinics were collapsed into palliative versus curative to identify potential differences based on prognosis. Analyses were conducted using SAS version 9.4 (Cary, NC). For the Chi-square analyses, the 5-point scales for questions 7 to 17 were collapsed to 3 -point scales, due to small cell size in some sub-groups.

\section{Results}

A total of 272 patients agreed to participate, with 222 (82\%) completing the survey. The $18 \%$ who did not complete it were interrupted due to the timing of their appointment, or they expressed difficulty in understanding the questions. Approximately $70 \%$ of those approached agreed to participate. Our demographic reporting (Table 1) was limited to age, gender, treatment stage, and clinic due to a substantial proportion of patients being reluctant to share income and education information, and patient-reported ambiguity over the classification of ethnicity (e.g. many fit within multiple categories).

Survey responses are summarized in Table 2, categorized by age, and palliative versus curative clinic. Additional file 1: Supplementary Table 1 presents the results (Q7-17) collapsed into 3-levels (i.e. one level combining very comfortable and comfortable responses, one level for neutral, and one level combining uncomfortable and very uncomfortable) with the same categories. Additional file 1: Supplementary Table 2 presents the responses categorized by individual clinic, treatment stage, and gender.

Overall, the majority of patients reported being comfortable with sharing their health information with their own institutional (UHN) researchers (Table 2; Q7-83\%, $p<0.001)$. Palliative patients were slightly more comfortable compared to curative patients ( $96 \%$ vs. $81 \%$ ). Younger patients ( $\leq 49$ years) were more uncomfortable than older patients $(50+$ years) with sharing even within their own hospital ( $13 \%$ vs. $2 \%, p<0.05$; Fig. 1a). More patients preferred a broad consent strategy over a studyspecific strategy (Table 2; Q5-56\% vs. 38\%), although $6 \%$ would not share at all. This trend was reported by
Table 1 Patient demographics of the 222 study participants

\begin{tabular}{lc}
\hline Demographic & $N(\%)$ \\
\hline Age & \\
$\leq 49$ & $38(17)$ \\
$50-74$ & $132(59)$ \\
$\geq 75$ & $48(21)$ \\
Rather not say & $4(2)$ \\
Gender & \\
Male & $112(50)$ \\
Female & $108(49)$ \\
Rather not say & $2(1)$ \\
Treatment stage & \\
Pre-treatment & $22(10)$ \\
Treatment & $87(40)$ \\
Follow-up & $113(50)$ \\
Clinic & \\
Breast & $49(22)$ \\
Lung & $45(20)$ \\
Prostate & $49(22)$ \\
Thyroid & $48(22)$ \\
Palliative & $25(11)$ \\
Other & $6(3)$ \\
\hline
\end{tabular}

patients aged $50-74$ years ( $55 \%$ broad vs. $39 \%$ study-specific consent), and patients $\geq 75$ years ( $72 \%$ broad vs. $24 \%$ study-specific consent), but reversed in younger patients aged $\leq 49$ years $(42 \%$ broad vs. $50 \%$ study-specific consent, $p<0.05$; Fig. 1b).

When categorized by age, several additional trends were observed (Fig. 1). The majority of patients $(63 \%$, $p<0.001)$ wished to be asked for permission before being entered into a contact pool (Q6). This was particularly notable for younger patients aged $\leq 49$ years at $76 \%$ (Fig. 1c). Additionally, most patients preferred the option to track PHI usage (Q18-61\%, $p<0.05)$, with the highest proportion again reported in the youngest patient group ( $\leq 49$ years: $71 \%$; $50-75$ years: $63 \%$; $75+$ years: $47 \%, p<0.01$; Fig. 1d). The most preferred method of tracking (Q20) was via an online electronic patient portal (35\%), followed by email (23\%), then standard mail (20\%). A majority of patients preferred to receive results of studies that have used their information or samples (Q19-70\%, $p<0.001)$. Once again, the highest proportion was observed in the youngest patients $(\leq 49$ years: 76\%; 50-74 years: $73 \%$; $75+$ years: $58 \%, p<0.05$; Fig. 1 e). This preference remained stable regardless of palliative $(60 \%)$ or curative $(71 \%)$ status. Interestingly, patients in the follow-up clinic were significantly more likely to wish to track their PHI use (Q18-72\%; $p<0.01$, and receive study results $(\mathrm{Q} 19-81 \% ; p<0.01)$ as compared to those in pre-treatment or treatment groups (Additional file 1: 
Table 2 Response results to survey questions

\begin{tabular}{|c|c|c|c|c|c|c|c|c|}
\hline \multicolumn{2}{|c|}{ Question } & \multirow{2}{*}{$\begin{array}{l}\text { Response } \\
\text { Share all information }\end{array}$} & \multirow{2}{*}{$\begin{array}{l}\text { Overall } \\
N=222\end{array}$} & \multirow{2}{*}{$\begin{array}{l}\text { Age } \leq 49 \\
N=38 \\
26(68)\end{array}$} & \multirow{2}{*}{$\begin{array}{l}\text { Age } 50-74 \\
N=132 \\
111(86)\end{array}$} & \multirow{2}{*}{$\begin{array}{l}\text { Age } \geq 75 \\
N=48 \\
38(79)\end{array}$} & \multirow{2}{*}{$\begin{array}{l}\text { Curative Clinic } \\
N=197 \\
154(79)\end{array}$} & \multirow{2}{*}{$\begin{array}{l}\text { Palliative Clinic } \\
N=25 \\
23(92)\end{array}$} \\
\hline Q1 & Your health information is & & & & & & & \\
\hline & divided into several different & Share no information & $12(5)$ & $4(11)$ & $4(3)$ & $3(6)$ & $12(6)$ & $0(0)$ \\
\hline & $\begin{array}{l}\text { sections (e.g. dlagnoses test } \\
\text { results and images such as }\end{array}$ & Share specific information & $30(14)$ & $8(21)$ & $14(11)$ & $7(15)$ & $28(14)$ & $2(8)$ \\
\hline & $\begin{array}{l}\text { x-rays or scans). Would you } \\
\text { like to: }\end{array}$ & No response & 3 & 0 & 3 & 0 & 3 & 0 \\
\hline \multirow[t]{4}{*}{ Q2 } & \multirow{4}{*}{$\begin{array}{l}\text { Your biological samples are } \\
\text { classified into several differ- } \\
\text { ent types (e.g. blood urine } \\
\text { tissues). Would you like to: }\end{array}$} & Share all information & $173(79)$ & $25(66)$ & $107(83)$ & $39(81)$ & $151(78)$ & $22(88)$ \\
\hline & & Share no information & $18(8)$ & $5(13)$ & $9(7)$ & $3(6)$ & $18(9)$ & $0(0)$ \\
\hline & & Share specific information & $28(13)$ & $8(21)$ & $13(10)$ & $6(13)$ & $25(13)$ & $3(12)$ \\
\hline & & No response & 3 & 0 & 3 & 0 & 3 & 0 \\
\hline \multirow[t]{4}{*}{ Q3 } & \multirow{4}{*}{$\begin{array}{l}\text { There are many different areas } \\
\text { of medical research (e.g. } \\
\text { research on cancer diabetes } \\
\text { reproductive disorders } \\
\text { genetic disorders heart dis- } \\
\text { ease etc.). Would you like to: }\end{array}$} & Share all information & $172(79)$ & $25(66)$ & $105(81)$ & $40(85)$ & $152(78)$ & $20(83)$ \\
\hline & & Share no information & $9(4)$ & $2(5)$ & $5(4)$ & $1(2)$ & $9(5)$ & $0(0)$ \\
\hline & & Share specific information & $37(17)$ & $11(29)$ & $19(15)$ & $6(13)$ & $33(17)$ & $4(17)$ \\
\hline & & No response & 4 & 0 & 3 & 1 & 3 & 1 \\
\hline \multirow[t]{3}{*}{ Q4 } & \multirow{3}{*}{$\begin{array}{l}\text { When asked for consent to } \\
\text { share your information or } \\
\text { samples would you like to } \\
\text { have an option to think } \\
\text { about the decision and be } \\
\text { asked again later? }\end{array}$} & Yes & $107(49)$ & $22(58)$ & $65(50)$ & $18(38)$ & $97(50)$ & $10(42)$ \\
\hline & & No & $111(51)$ & $16(42)$ & $64(50)$ & $29(62)$ & $97(50)$ & $14(58)$ \\
\hline & & No response & 4 & $0(0)$ & 3 & 1 & 3 & 1 \\
\hline \multirow[t]{4}{*}{ Q5 } & \multirow{4}{*}{$\begin{array}{l}\text { Your health information and } \\
\text { samples are often requested } \\
\text { for future studies. Would you } \\
\text { like to: }\end{array}$} & Broad consent & $119(56)$ & $16(42)$ & $69(55)$ & $33(72)$ & $103(54)$ & $16(67)$ \\
\hline & & Study-specific consent & $80(38)$ & $19(50)$ & $49(39)$ & $11(24)$ & $74(39)$ & $6(25)$ \\
\hline & & Would not share & $14(6)$ & $3(8)$ & $8(6)$ & $2(4)$ & $12(6)$ & $2(8)$ \\
\hline & & No response & 9 & 0 & 6 & 2 & 8 & 1 \\
\hline \multirow[t]{3}{*}{ Q6 } & \multirow{3}{*}{$\begin{array}{l}\text { A CONTACT POOL may be } \\
\text { created with patient names } \\
\text { phone numbers and key } \\
\text { pieces of health information. } \\
\text { UHN Researchers with ethical } \\
\text { approval for their studies } \\
\text { could search this pool to } \\
\text { find participants. Would you } \\
\text { prefer to be: }\end{array}$} & Asked for permission & $134(63)$ & $29(76)$ & $74(59)$ & $28(61)$ & $127(66)$ & $7(30)$ \\
\hline & & Automatically entered & $80(37)$ & $9(24)$ & $52(41)$ & $18(39)$ & $64(34)$ & $16(70)$ \\
\hline & & No response & 8 & 0 & 6 & 2 & 6 & 2 \\
\hline \multirow[t]{6}{*}{ Q7 } & \multirow{6}{*}{$\begin{array}{l}\text { How comfortable are you with } \\
\text { providing consent for your } \\
\text { information or samples to } \\
\text { be shared with Researchers } \\
\text { within UHN? }\end{array}$} & Very Comfortable & $121(55)$ & $17(45)$ & $76(58)$ & $26(55)$ & $108(55)$ & $13(52)$ \\
\hline & & Comfortable & $62(28)$ & $10(26)$ & $40(30)$ & $11(23)$ & $51(26)$ & $11(44)$ \\
\hline & & Neutral & $30(14)$ & $6(16)$ & $14(11)$ & $10(21)$ & $29(15)$ & $1(4)$ \\
\hline & & Uncomfortable & $5(2)$ & $3(8)$ & $2(2)$ & $0(0)$ & $5(3)$ & $0(0)$ \\
\hline & & Very Uncomfortable & $3(1)$ & $2(5)$ & $0(0)$ & $0(0)$ & $3(2)$ & $0(0)$ \\
\hline & & No response & 1 & 0 & 0 & 1 & 1 & 0 \\
\hline \multirow[t]{5}{*}{ Q8 } & \multirow{5}{*}{$\begin{array}{l}\text { How comfortable are you with } \\
\text { providing consent for your } \\
\text { information or samples to be } \\
\text { shared with Researchers at } \\
\text { other hospital-based } \\
\text { research institutes? }\end{array}$} & Very Comfortable & $85(38)$ & $12(32)$ & $52(39)$ & $19(40)$ & $76(39)$ & $9(36)$ \\
\hline & & Comfortable & $68(31)$ & $9(24)$ & $45(34)$ & $14(29)$ & $55(28)$ & $13(52)$ \\
\hline & & Neutral & $44(20)$ & $11(29)$ & $24(18)$ & $9(19)$ & $42(21)$ & $2(8)$ \\
\hline & & Uncomfortable & $17(8)$ & $3(8)$ & $10(8)$ & $3(6)$ & $16(8)$ & $1(4)$ \\
\hline & & Very Uncomfortable & $8(4)$ & $3(8)$ & $1(1)$ & $3(6)$ & $8(4)$ & $0(0)$ \\
\hline \multirow[t]{6}{*}{ Q9 } & \multirow{6}{*}{$\begin{array}{l}\text { How comfortable are you with } \\
\text { providing consent for your } \\
\text { information or samples to be } \\
\text { shared with Researchers at } \\
\text { universities? }\end{array}$} & Very Comfortable & $71(33)$ & $11(29)$ & $45(35)$ & $13(28)$ & $65(33)$ & $6(27)$ \\
\hline & & Comfortable & $82(38)$ & $14(37)$ & $50(39)$ & $18(38)$ & $67(34)$ & $15(68)$ \\
\hline & & Neutral & $39(18)$ & $9(24)$ & $21(16)$ & $8(17)$ & $39(20)$ & $0(0)$ \\
\hline & & Uncomfortable & $18(8)$ & $1(3)$ & $11(9)$ & $6(13)$ & $18(9)$ & $0(0)$ \\
\hline & & Very Uncomfortable & $8(4)$ & $3(8)$ & $2(2)$ & $2(4)$ & $7(4)$ & $1(5)$ \\
\hline & & No response & 4 & 0 & 3 & 1 & 1 & 3 \\
\hline
\end{tabular}


Table 2 (continued)

\begin{tabular}{|c|c|c|c|c|c|c|c|c|}
\hline \multicolumn{2}{|c|}{ Question } & \multirow{2}{*}{$\begin{array}{l}\text { Response } \\
\text { Very Comfortable }\end{array}$} & \multirow{2}{*}{$\begin{array}{l}\text { Overall } \\
N=222\end{array}$} & \multirow{2}{*}{$\begin{array}{l}\text { Age } \leq 49 \\
N=38 \\
6(16)\end{array}$} & \multirow{2}{*}{$\begin{array}{l}\text { Age } 50-74 \\
N=132 \\
20(15)\end{array}$} & \multirow{2}{*}{$\begin{array}{l}\text { Age } \geq 75 \\
N=48 \\
8(17)\end{array}$} & \multirow{2}{*}{$\begin{array}{l}\text { Curative Clinic } \\
N=197 \\
32(16)\end{array}$} & \multirow{2}{*}{$\begin{array}{l}\text { Palliative Clinic } \\
N=25 \\
3(13)\end{array}$} \\
\hline Q10 & How comfortable are you with & & & & & & & \\
\hline & $\begin{array}{l}\text { providing consent for your } \\
\text { information or samples to be }\end{array}$ & Comfortable & $24(11)$ & $3(8)$ & $15(12)$ & $5(11)$ & $19(10)$ & $5(22)$ \\
\hline & $\begin{array}{l}\text { shared with For-profit busi- } \\
\text { nesses (e.g. drug or insurance }\end{array}$ & Neutral & $49(22)$ & $12(32)$ & $25(19)$ & $12(26)$ & $42(21)$ & $7(30)$ \\
\hline & companies such as Pfizer)? & Uncomfortable & $51(23)$ & $7(18)$ & $33(25)$ & $11(23)$ & $44(22)$ & $7(30)$ \\
\hline & & Very Uncomfortable & $60(27)$ & $10(26)$ & $37(28)$ & $11(23)$ & $59(30)$ & $1(4)$ \\
\hline & & No response & 3 & 0 & 2 & 1 & 1 & 2 \\
\hline \multirow[t]{6}{*}{ Q11 } & \multirow{6}{*}{$\begin{array}{l}\text { How comfortable are you } \\
\text { with providing consent for } \\
\text { your information or samples } \\
\text { to be shared with Not-for- } \\
\text { profit businesses (e.g. Heart } \\
\text { and Stroke Foundation of } \\
\text { Canada)? }\end{array}$} & Very Comfortable & $64(29)$ & $9(24)$ & $41(32)$ & $12(26)$ & $60(31)$ & $4(16)$ \\
\hline & & Comfortable & $61(28)$ & $6(16)$ & $36(28)$ & $19(40)$ & $46(24)$ & $15(60)$ \\
\hline & & Neutral & $50(23)$ & $12(32)$ & $25(19)$ & $12(26)$ & $48(25)$ & $2(8)$ \\
\hline & & Uncomfortable & $31(14)$ & $9(24)$ & $20(15)$ & $2(4)$ & $28(14)$ & $3(12)$ \\
\hline & & Very Uncomfortable & $13(6)$ & $2(5)$ & $8(6)$ & $2(4)$ & $12(6)$ & $1(4)$ \\
\hline & & No response & 3 & 0 & 2 & 1 & 3 & 0 \\
\hline \multirow[t]{6}{*}{ Q12 } & \multirow{6}{*}{$\begin{array}{l}\text { How comfortable are you with } \\
\text { providing consent for your } \\
\text { information or samples to be } \\
\text { shared Provincially (i.e. within } \\
\text { Ontario)? }\end{array}$} & Very Comfortable & $52(24)$ & $7(18)$ & $33(25)$ & $10(21)$ & $47(24)$ & $5(20)$ \\
\hline & & Comfortable & $65(30)$ & $8(21)$ & $39(30)$ & $18(38)$ & $50(26)$ & $15(60)$ \\
\hline & & Neutral & $58(26)$ & $14(37)$ & $34(26)$ & $10(21)$ & $56(29)$ & $2(8)$ \\
\hline & & Uncomfortable & $28(13)$ & $6(16)$ & $16(12)$ & $6(13)$ & $26(13)$ & $2(8)$ \\
\hline & & Very Uncomfortable & $16(7)$ & $3(8)$ & $8(6)$ & $3(6)$ & $15(8)$ & $1(4)$ \\
\hline & & No response & 3 & 0 & 2 & 1 & 3 & 0 \\
\hline \multirow[t]{6}{*}{ Q13 } & \multirow{6}{*}{$\begin{array}{l}\text { How comfortable are you with } \\
\text { providing consent for your } \\
\text { information or samples to be } \\
\text { shared Nationally (i.e. within } \\
\text { Canada)? }\end{array}$} & Very Comfortable & $52(24)$ & $7(18)$ & $35(27)$ & $9(19)$ & $47(24)$ & $5(20)$ \\
\hline & & Comfortable & $64(29)$ & $9(24)$ & $38(29)$ & $16(34)$ & $50(26)$ & $14(56)$ \\
\hline & & Neutral & $57(26)$ & $13(34)$ & $33(25)$ & $11(23)$ & $54(28)$ & $3(12)$ \\
\hline & & Uncomfortable & $29(13)$ & $5(13)$ & $16(12)$ & $7(15)$ & $27(14)$ & $2(8)$ \\
\hline & & Very Uncomfortable & $17(8)$ & $4(11)$ & $8(6)$ & $4(9)$ & $16(8)$ & $1(4)$ \\
\hline & & No response & 3 & 0 & 2 & 1 & 3 & 0 \\
\hline \multirow[t]{6}{*}{ Q14 } & \multirow{6}{*}{$\begin{array}{l}\text { How comfortable are you with } \\
\text { providing consent for your } \\
\text { information or samples to } \\
\text { be shared Internationally (i.e. } \\
\text { around the world)? }\end{array}$} & Very Comfortable & $44(20)$ & $7(18)$ & $28(22)$ & $8(17)$ & $40(21)$ & $4(16)$ \\
\hline & & Comfortable & $41(19)$ & $7(18)$ & $26(20)$ & $8(17)$ & $30(15)$ & $11(44)$ \\
\hline & & Neutral & $53(24)$ & $11(29)$ & $29(22)$ & $13(28)$ & $49(25)$ & $4(16)$ \\
\hline & & Uncomfortable & $46(21)$ & $6(16)$ & $29(22)$ & $10(21)$ & $42(22)$ & $4(16)$ \\
\hline & & Very Uncomfortable & $35(16)$ & $7(18)$ & $18(14)$ & $8(17)$ & $33(17)$ & $2(8)$ \\
\hline & & No response & 3 & 0 & 2 & 1 & 3 & 0 \\
\hline \multirow[t]{5}{*}{ Q15 } & \multirow{5}{*}{$\begin{array}{l}\text { Sometimes for-profit compa- } \\
\text { nies develop partnerships } \\
\text { with UHN and we work } \\
\text { together on medical research } \\
\text { projects. How comfortable } \\
\text { are you consenting to share } \\
\text { your information or samples } \\
\text { for these projects? }\end{array}$} & Very Comfortable & $38(17)$ & $6(16)$ & $25(19)$ & $6(13)$ & $35(18)$ & $3(12)$ \\
\hline & & Comfortable & $73(33)$ & $11(29)$ & $43(33)$ & $18(38)$ & $57(29)$ & $16(64)$ \\
\hline & & Neutral & $48(22)$ & $9(24)$ & $28(21)$ & $11(23)$ & $45(23)$ & $3(12)$ \\
\hline & & Uncomfortable & $33(15)$ & $6(16)$ & $18(14)$ & $8(17)$ & $30(15)$ & $3(12)$ \\
\hline & & Very Uncomfortable & $30(14)$ & $6(16)$ & $18(14)$ & $5(10)$ & $30(15)$ & $0(0)$ \\
\hline \multirow[t]{6}{*}{ Q16 } & \multirow{6}{*}{$\begin{array}{l}\text { Sometimes for-profit com- } \\
\text { panies ask UHN for health } \\
\text { information or samples. How } \\
\text { comfortable are you consent- } \\
\text { ing to share your information } \\
\text { or samples with these com- } \\
\text { panies if UHN is not directly } \\
\text { involved in their work? }\end{array}$} & Very Comfortable & $25(12)$ & $2(6)$ & $17(13)$ & $6(13)$ & $22(12)$ & $3(12)$ \\
\hline & & Comfortable & $43(20)$ & $6(17)$ & $29(22)$ & $7(15)$ & $34(18)$ & $9(36)$ \\
\hline & & Neutral & $37(17)$ & $7(20)$ & $17(13)$ & $13(28)$ & $35(18)$ & $2(8)$ \\
\hline & & Uncomfortable & $53(25)$ & $10(29)$ & $34(26)$ & $9(20)$ & $43(23)$ & $10(40)$ \\
\hline & & Very Uncomfortable & $57(27)$ & $10(29)$ & $34(26)$ & $11(24)$ & $56(29)$ & $1(4)$ \\
\hline & & No response & 7 & 3 & 1 & 2 & 7 & 0 \\
\hline
\end{tabular}


Table 2 (continued)

\begin{tabular}{|c|c|c|c|c|c|c|c|c|}
\hline \multicolumn{2}{|c|}{ Question } & \multirow{2}{*}{$\begin{array}{l}\text { Response } \\
\text { Very Comfortable }\end{array}$} & \multirow{2}{*}{$\begin{array}{l}\text { Overall } \\
N=222\end{array}$} & \multirow{2}{*}{$\begin{array}{l}\text { Age } \leq 49 \\
N=38 \\
4(11)\end{array}$} & \multirow{2}{*}{$\begin{array}{l}\text { Age } 50-74 \\
N=132 \\
19(15)\end{array}$} & \multirow{2}{*}{$\begin{array}{l}\text { Age } \geq 75 \\
N=48 \\
6(13)\end{array}$} & \multirow{2}{*}{$\begin{array}{l}\text { Curative Clinic } \\
N=197 \\
25(13)\end{array}$} & \multirow{2}{*}{$\begin{array}{l}\text { Palliative Clinic } \\
N=25 \\
4(17)\end{array}$} \\
\hline Q17 & Sometimes medical research & & & & & & & \\
\hline & or samples at UHN leads to & Comfortable & $52(24)$ & $6(16)$ & $32(24)$ & $12(26)$ & $42(21)$ & $10(42)$ \\
\hline & $\begin{array}{l}\text { discoveries that are commer- } \\
\text { cialized and sold for-profit in }\end{array}$ & Neutral & $51(23)$ & $11(29)$ & $33(25)$ & $7(15)$ & $48(24)$ & $3(13)$ \\
\hline & the future. How do you feel & Uncomfortable & $47(21)$ & $8(21)$ & $25(19)$ & $14(30)$ & $41(21)$ & $6(25)$ \\
\hline & your information or samples & Very Uncomfortable & $41(19)$ & $9(24)$ & $22(17)$ & $8(17)$ & $40(20)$ & $1(4)$ \\
\hline & Deing involved in this? & No response & 2 & 0 & 1 & 1 & 1 & 1 \\
\hline \multirow[t]{4}{*}{ Q18 } & \multirow{4}{*}{$\begin{array}{l}\text { Would you like to be able to } \\
\text { track who is using your infor- } \\
\text { mation or samples and what } \\
\text { they are using it for? }\end{array}$} & Yes & $134(61)$ & $27(71)$ & $83(63)$ & $22(47)$ & $124(63)$ & $10(40)$ \\
\hline & & No & $77(35)$ & $7(18)$ & $45(34)$ & $24(51)$ & $63(32)$ & $14(56)$ \\
\hline & & $\begin{array}{l}\text { Not applicable. I would not } \\
\text { share at all }\end{array}$ & $10(5)$ & $4(11)$ & $4(3)$ & $1(2)$ & $9(5)$ & $1(4)$ \\
\hline & & No response & 1 & 0 & 0 & 1 & 1 & 0 \\
\hline \multirow[t]{3}{*}{ Q19 } & \multirow{3}{*}{$\begin{array}{l}\text { Would you like to be notified } \\
\text { with the results of studies } \\
\text { that have used your informa- } \\
\text { tion or samples? }\end{array}$} & Yes & $155(70)$ & $29(76)$ & $96(73)$ & $28(58)$ & $140(71)$ & $15(60)$ \\
\hline & & No & $57(26)$ & $5(13)$ & $32(24)$ & $19(40)$ & $48(24)$ & $9(36)$ \\
\hline & & $\begin{array}{l}\text { Not applicable. I would not } \\
\text { share at all }\end{array}$ & $10(5)$ & $4(11)$ & $4(3)$ & $1(2)$ & $9(5)$ & $1(4)$ \\
\hline \multirow[t]{6}{*}{ Q20 } & \multirow{6}{*}{$\begin{array}{l}\text { If you do want to be notified of } \\
\text { study results how would you } \\
\text { like to be notified? }\end{array}$} & $\begin{array}{l}\text { Online via an electronic patient } \\
\text { portal }\end{array}$ & $76(35)$ & $15(39)$ & $51(39)$ & $8(17)$ & $66(34)$ & $10(40)$ \\
\hline & & Online via email & $50(23)$ & $14(37)$ & $29(22)$ & $7(15)$ & $47(24)$ & $3(12)$ \\
\hline & & Standard mail & $43(20)$ & $3(8)$ & $25(19)$ & $15(31)$ & $39(20)$ & $4(16)$ \\
\hline & & $\begin{array}{l}\text { I do NOT want to be notified of } \\
\text { study results }\end{array}$ & $40(18)$ & $4(11)$ & $20(15)$ & $15(31)$ & $34(17)$ & $6(24)$ \\
\hline & & $\begin{array}{l}\text { Not applicable. I would not } \\
\text { share at all }\end{array}$ & $11(5)$ & $2(5)$ & $5(4)$ & $3(6)$ & $9(5)$ & $2(8)$ \\
\hline & & No response & 2 & 0 & 2 & 0 & 2 & 0 \\
\hline
\end{tabular}

Table 2). In terms of selectivity, $14 \%$ of patients preferred the option to select parts of their health information to share (Q1), 13\% wished to select specific components of their biological samples to share (Q2), and 17\% desired the option to select specific areas of research to share (Q3) (all Table 2). Females were significantly more likely to select components of health information to share than males (Q1-20\% vs. 7\%; $p<0.01$; Additional file 1: Table 2).

Intended recipient of PHI was a very important consideration. Few patients overall were comfortable sharing with commercial companies (Q10-27\%); with 51\% reporting being uncomfortable, and $22 \%$ offering neutral responses. This is clearly illustrated in Fig. 2, whereby the percentage of patients reporting comfort as a function of recipients varied significantly. Comfort was highest with respect to sharing with researchers at the respondents' own health organization (83\%), but dropped to $70 \%$ for academic researchers, $57 \%$ for non-profit companies, and plummeted to $27 \%$ with for-profit commercial companies. When the host institution had a collaborative partnership with the companies, $50 \%$ of patients were comfortable, $22 \%$ neutral, and $28 \%$ were uncomfortable sharing (Q15). Without direct institutional involvement however, only $32 \%$ were comfortable, $17 \%$ neutral, and $51 \%$ were uncomfortable in sharing with commercial companies (Q16). Once again, younger patients ( $\leq 49$ years) were more likely to report discomfort in sharing PHI with commercial companies without host institution involvement compared to the oldest group ( $75+$ years; $57 \%$ vs. $43 \%$ ) (Fig. 1f). Significant differences were reported for Q16 by gender and treatment stage (Additional file 1: Table 2). Females were more likely to be uncomfortable than comfortable (57\% vs. $44 \%$, $p<0.05)$, whereas males were more likely to be comfortable than uncomfortable ( $40 \%$ vs. $23 \%, p<0.01$ ). Finally, significantly more patients in the follow-up stage were uncomfortable (60\%) when compared to pre-treatment $(50 \%)$ or active treatment $(40 \% ; p<0.05)$ cohorts.

\section{Discussion}

The vast majority (83\%) of participants were comfortable sharing PHI with researchers at their own institution, while most wished to be asked first and apprised of its potential uses. This observation is reassuring, and reflects a generally positive attitude towards locally conducted 


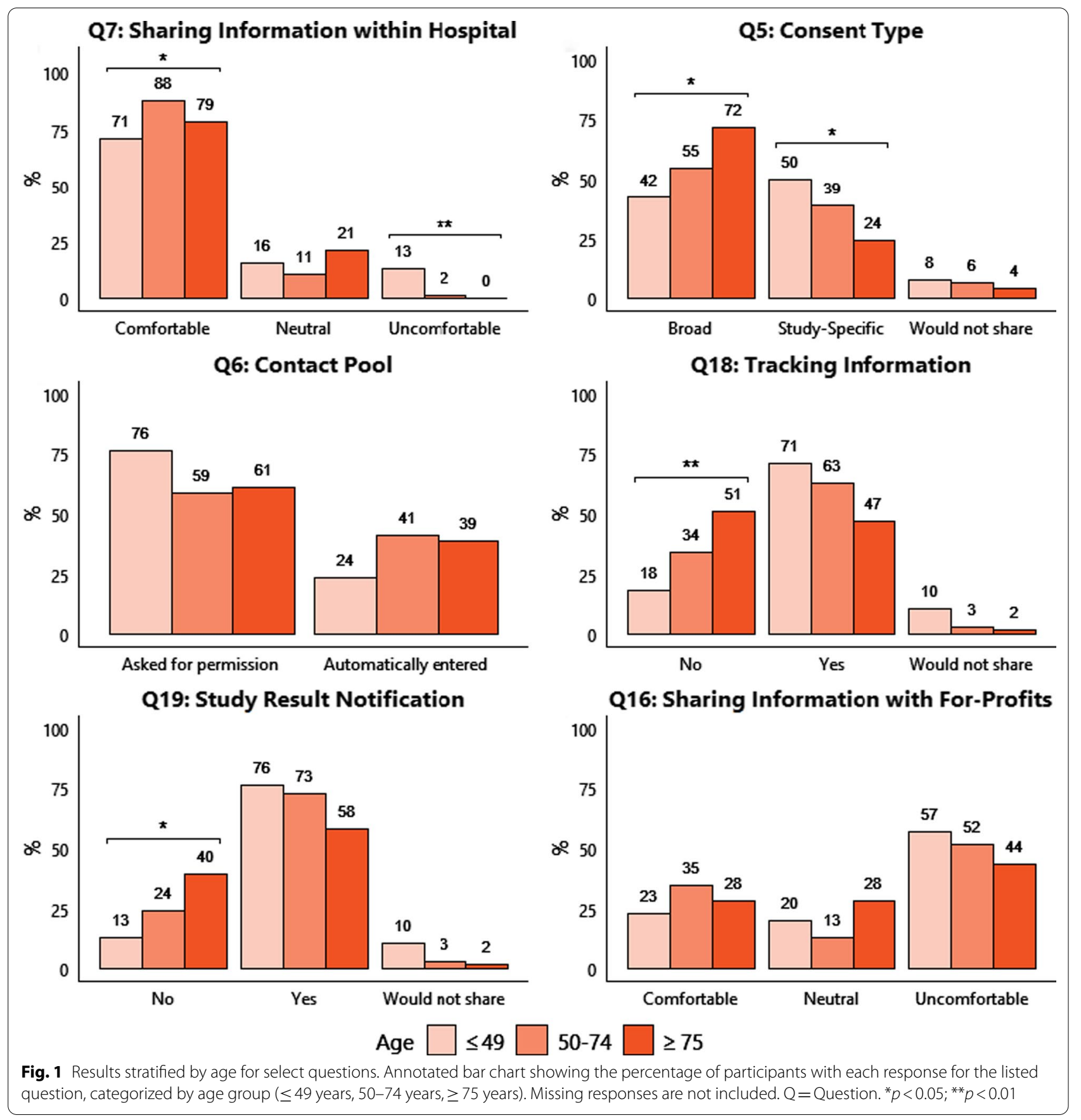

research. The fact however, that a minority (17\%) did not report comfort sharing PHI with even host institutional researchers is noteworthy, particularly since these participants had already agreed to complete a research survey. Though willingness to complete a research survey does not necessarily correlate with willingness to share PHI, it seems reasonable to suggest that those already participating in research may hold more favorable attitudes to sharing their PHI with researchers. Thus, reality may reflect a higher proportion of the patient population that is not comfortable sharing PHI even with local researchers. This underscores the importance of addressing this challenge in organizational policy, applicable to even low-risk retrospective studies.

One of our key observations relates to the effect of age on PHI sharing. Not only were younger patients more likely to report discomfort sharing with host institutional researchers and commercial companies without host 


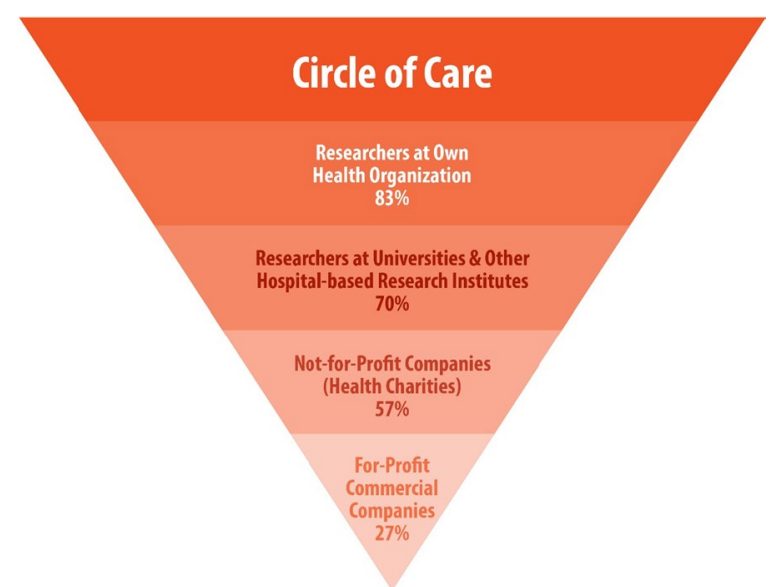

Fig. 2 Percentage of patients reporting comfort sharing $\mathrm{PHI}$ as a function of recipient. Inverted pyramid chart showing the progressive decline in percentage of participants reporting comfort sharing with recipients outside the circle of care from within one's own health organization (83\%) to for-profit commercial companies (27\%)

institutional involvement, they were also more likely to prefer: (a) study-specific consent; (b) to be asked for permission before contact pool entry; (c) the ability to track PHI use; and (d) to receive study results. This is compelling evidence of a generational shift whereby younger patients raised in cultures of increasingly immersive technology (particularly more so than those $75+$ years of age) are more hesitant to share, and desire more control over the use of their information. Our findings are consistent with previous observations that younger people prefer more control with respect to research participation than older individuals [18, 21, 24]. Whether these preferences will evolve over time remains to be seen, but it is possible that being raised in a technological era with platforms such as Facebook ${ }^{\mathrm{TM}}$ and Google ${ }^{\mathrm{TM}}$ renders this generation less trusting of institutions. Indeed, trust in institutions is commonly lowest amongst younger populations $[27,28]$. It may be likely that this desire will be sustained as these individuals age and become major users of health care. It would be prudent, therefore, for health care organizations to acknowledge this trend, and to adapt consent policies correspondingly.

In our study, significantly more women preferred specific consent options and held higher levels of discomfort sharing PHI than did men (Q1; Q16), a finding which has been noted previously [19, 24]. Acknowledgement by health organizations of these gender differences is a step toward greater respect and inclusion; reforming existing policies to be more equitable and forward thinking would constitute significant progress.

Given that substantial groups of patients prefer studyspecific consent (38\%), and would like the opportunity to consider their consent decisions and be asked again later (49\%), further exploration of how practicably to provide these options is warranted. These findings are consistent with previously reported studies [22, 23, 29, 30] reflecting many patients' general reluctance for a broad consent or no-consent model.

Debate has also been ongoing regarding opt-in versus opt-out approaches for research contact pools. Some major health organizations employ or advocate for an opt-out approach whereby patient names and select PHI (e.g. age, gender, diagnosis, clinics \& programs accessed, etc.) are automatically entered into databases, and patients can contact the institution to opt-out [31]. While this streamlines the process for researchers, some have challenged the ethical defensibility and legality of sharing potentially sensitive PHI outside the circle of care without active consent [20]. The current data provide strong support for an opt-in strategy, wherein a majority of respondents (63\%), and an even greater majority of younger respondents (76\%) preferred to be asked for permission before entry (Q6). This corroborates previously reported observations of patients preferring opt-in [9, $15,21,32]$. To return to our earlier observation, it is particularly notable that the majority of patients who already agreed to participate in a research survey still wished to be asked permission before contact pool entry. One could reasonably infer that an even higher percentage of those not partaking in research surveys would prefer to be asked for permission. The success of medical research hinges on public trust in health institutions. Our findings lead us to assert that the precarious assumption of consent under an opt-out system risks undermining patients' trust in research hospitals - trust that has been tested in a number of high profile cases and is not easily regained once eroded [1, 2].

The considerable level of patient discomfort with PHI being shared with for-profit commercial companies warrants broad attention. More than half of our patients (51\%) reported being uncomfortable sharing with industry recipients (Q10; Fig. 2). This aligns with previous investigations in the cancer patient population, whereby low levels of trust towards industry and insurance recipients have also been reported [23]. While it appears that direct collaborations between health organizations and industry may mitigate some level of discomfort, it does not diminish it completely (51\% to $28 \%$ ). These results corroborate a significant and growing body of evidence that suggests that patients desire more transparency and control over commercial PHI use [9, 11, 15, 18-20, 32-38]. We recommend that patients be provided with an active opt-in choice as to whether they wish to share PHI with commercial companies. While this proposition is likely to face strong resistance within some research 
and industry circles, we submit that the continuation of a practice known to cause significant discomfort in the majority of patients is a governance misstep by healthcare organizations which purport to be committed to patient-centered care and respectful of the principle of patient self-determination. At the very least, it seems uncontroversial to suggest that patients should be given the option to choose whether or not their PHI can be shared with industry when their own health organization is not an active research partner.

Our results also reflect a substantial preference to be informed of secondary PHI use (61\%), and to receive results of studies using their PHI (70\%). This indicates that patients truly take an interest in research uses of PHI, and in clinical research findings in general. These observations again align with existing evidence; in a 2019 broad systematic review, participants almost never expected financial compensation, but "they demanded information on the research results" [30]. Admittedly, respecting this preference will require investment in technological tracking systems, but dynamic digital platforms do exist and should be employed [39]. Although significant work is required upfront, these investments promise significant yields in the long term; patients previously reluctant to share may become more willing if more information is provided. At minimum, health organizations could ensure that results are accessible through a publically available database. It is notable that higher proportions of patients in follow-up stages of care prefer to track PHI use (72\%) and to receive study results (81\%). To our knowledge, this is a novel finding indicating that as patients approach the end of their care journey, the desire for information not only remains, but becomes more pronounced. This underscores the enduring nature of this preference, and further emphasizes the need for health care organizations to provide meaningful options. It is also important to highlight that the majority of patients with a palliative diagnosis $(60 \% ; n=25)$ also desired the option to receive study results. The opportunity to learn how one's own PHI has contributed to the advancement of medical science may hold value and meaning for patients, including those at the end of life.

Our findings should be interpreted within the context of several limitations. Our participants were limited to those with cancer in radiation oncology clinics at a large academic centre, within a publically funded healthcare system. As such, we cannot be certain that preferences can be generalized to more diverse populations. We also acknowledge that patients may not have had extensive background knowledge on the benefits and drawbacks of each consent strategy. Although we endeavored to provide as much information as possible, we were cognizant of patients' limited time, and kept the survey to a palatable 10-min. Finally, as we have noted, our findings reflect only the preferences of patients who were willing to participate in a survey. While we have attempted to extrapolate the implications for patients not interested in research participation, we acknowledge the more speculative nature of these observations.

\section{Conclusions}

Our results underscore the importance of patient-centered consent and data governance policies that accurately reflect the identified preferences of patients. We note a consistent desire for greater transparency and autonomy, and our results particularly reveal a generational shift wherein younger patients prefer more informed consent options. Multiple factors must be considered including the consent process itself, the technological infrastructure to operationalize, and the nature of the broader healthcare system. Amongst the most readily achievable changes, we strongly recommend: (a) opt-in approaches to seek permission for research contact; and (b) the provision of genuine opportunities for uncertain patients to consider their consent decisions and revisit them later. While the following introduce more complexity, we also recommend providing options to choose: (a) broad or study-specific consent; (b) the conditions under which PHI may be shared with commercial companies; (c) whether to track secondary PHI use; and (d) whether to receive results of studies using PHI. We would be remiss to allow these results to reverberate in an esoteric echo chamber; further work must uncover strategies to translate these findings into effective policy changes. While this seems like a vast undertaking, the very technological advancements that have prompted the need for massive volumes of PHI can no doubt be applied to the design and implementation of modern consent platforms that exemplify a respect for well-identified patient values and preferences.

\section{Appendix 1 \\ Survey}

Hello and welcome,

You are being invited to participate in this survey because you are a patient at the Princess Margaret Cancer Centre within the University Health Network (UHN). It will only take about $10 \mathrm{~min}$ and your answers are anonymous (i.e., not linked to your name or medical record).

During your care at UHN, health information (e.g., your medical record with diagnoses, test results, and images such as x-rays), and biological samples (e.g., blood, tissues, or bodily fluids drawn for medical procedures) are collected and stored. The main purpose of 
collecting and storing your information and samples is for your own treatment and care.

Your health information and biological samples are also very valuable for other purposes. They can be used to help find new ways to detect, treat, prevent, and possibly cure many health-related problems such as cancer, diabetes, and heart disease. Researchers within UHN, and at other hospital-based research institutes, universities, and health-related companies request access to your information and samples for these reasons. The purpose of this survey is to help us understand your preferences on the way we ask for your consent to share.

When you consent to sharing your health information or samples, security measures are in place to protect your privacy including removing your name and anything that could directly identify you. There is still a small risk that donated information or samples could be traced back to you.

The choice to do this survey is completely up to you. Your decision will not affect your treatment or care in any way. During the completion of the survey, you are free to withdraw at any time and your answers will be deleted. There are no known risks or direct benefits to participating. If you consent to participating in this survey, please answer the questions on the following pages.

Thank you very much!

\section{Section 1: Asking for your Consent to Share}

1. Your health information is divided into several different sections (e.g., diagnoses, test results, and images such as $\mathrm{x}$-rays or scans). Would you like to:

a. Share ALL of your health information for research

b. Share NONE of your health information for research

c. CHOOSE SPECIFIC PARTS of your health information to share for research

2. Your biological samples are classified into several different types (e.g., blood, urine, tissues). Would you like to:

a. Share ALL your biological samples for research

b. Share NONE of your biological samples for research

c. CHOOSE SPECIFIC PARTS of your biological samples to share for research

3. There are many different areas of medical research (e.g., research on cancer, diabetes, reproductive dis- orders, genetic disorders, heart disease, etc.). Would you like to:

a. Share with ALL areas of research

b. Share with NO areas of research

c. CHOOSE SPECIFIC AREAS of research to share with

4. When asked for consent to share your information or samples, would you like to have an option to think about the decision and be asked again later?
a. Yes
b. No

5. Your health information and samples are often requested for future studies. Would you like to:
a. Be asked for consent ONCE for ALL FUTURE STUDIES. You are not given study details
b. Be contacted with details about each study and asked for consent EACH TIME
c. Not Applicable. I would NOT share at all

6. A CONTACT POOL may be created with patient names, phone numbers, and key pieces of health information (e.g., "breast cancer" or "depression" or "family support clinic"). UHN Researchers with ethical approval for their studies could search this pool to find participants. Would you prefer to be:

a. ASKED FOR YOUR PERMISSION and only entered in the pool if you say yes

b. AUTOMATICALLY ENTERED in the pool. You are given a form with a number to call if you'd like to be removed

\section{Section 2: Recipients}

With security measures in place to protect your privacy including removing your name and anything that could directly identify you (though there is still a small risk that your information or samples could be traced back to you), please tell us how comfortable you feel sharing your information or samples with the following recipients.

How comfortable are you with providing consent for your information or samples to be shared with Researchers within UHN?
a. Very Comfortable
b. Comfortable
c. Neutral
d. Uncomfortable 


\section{e. Very Uncomfortable}

How comfortable are you with providing consent for your information or samples to be shared with Researchers at other hospital-based research institutes?
a. Very Comfortable
b. Comfortable
c. Neutral
d. Uncomfortable
e. Very Uncomfortable

How comfortable are you with providing consent for your information or samples to be shared with Researchers at universities?
a. Very Comfortable
b. Comfortable
c. Neutral
d. Uncomfortable
e. Very Uncomfortable

How comfortable are you with providing consent for your information or samples to be shared with For-profit businesses (e.g., drug or insurance companies such as Pfizer)?
a. Very Comfortable
b. Comfortable
c. Neutral
d. Uncomfortable
e. Very Uncomfortable

How comfortable are you with providing consent for your information or samples to be shared with Not-forprofit businesses (e.g., Heart and Stroke Foundation of Canada)?
a. Very Comfortable
b. Comfortable
c. Neutral
d. Uncomfortable
e. Very Uncomfortable

How comfortable are you with providing consent for your information or samples to be shared Provincially (i.e., within Ontario)?
a. Very Comfortable
b. Comfortable
c. Neutral
d. Uncomfortable
e. Very Uncomfortable

How comfortable are you with providing consent for your information or samples to be shared Nationally (i.e., within Canada)?
a. Very Comfortable
b. Comfortable
c. Neutral
d. Uncomfortable
e. Very Uncomfortable

How comfortable are you with providing consent for your information or samples to be shared Internationally (i.e., around the world)?
a. Very Comfortable
b. Comfortable
c. Neutral
d. Uncomfortable
e. Very Uncomfortable

\section{Section 3: Commercialization}

When medical discoveries are made such as new treatments or cures for diseases, commercialization (i.e., selling for money) helps the discoveries to reach and help a great number of people. It also means that researchers and commercial companies may benefit financially. Patients who contribute their health information or samples do not get any money from this commercialization. We would like to understand how you feel about consenting to your health information or samples being used for projects that involve commercialization.

1. Sometimes for-profit companies (e.g., drug or insurance companies) develop partnerships with UHN and we work together on medical research projects. How comfortable are you consenting to share your information or samples (with your name and direct identifiers removed) for these projects?
a. Very Comfortable
b. Comfortable
c. Neutral
d. Uncomfortable
e. Very Uncomfortable

2. Sometimes for-profit companies (e.g., drug or insurance companies) ask UHN for health information or samples. How comfortable are you consenting to share your information or samples (with your name and direct identifiers removed) with these companies if $\mathrm{UHN}$ is not directly involved in their work? 

a. Very Comfortable
b. Comfortable
c. Neutral
d. Uncomfortable
e. Very Uncomfortable

3. Sometimes medical research using health information or samples at UHN leads to discoveries that are commercialized and sold for-profit in the future. How do you feel about consenting to share your information or samples (with your name and direct identifiers removed) being involved in this?
a. Very Comfortable
b. Comfortable
c. Neutral
d. Uncomfortable

4. Very Uncomfortable

\section{Section 4: Tracking sharing \& results}

1. Would you like to be able to track who is using your information or samples and what they are using it for?
a. Yes
b. No
c. Not Applicable. I would not share at all

2. Would you like to be notified with the results of studies that have used your information or samples?
a. Yes
b. No
c. Not Applicable. I would not share at all

3. If you do want to be notified of study results, how would you like to be notified?
a. Online via an electronic patient portal (i.e., a secure website that allows you to track your per- sonal health record)
b. Online via email
c. Standard mail
d. I do NOT want to be notified of study results
e. Not Applicable. I would not share at all

\section{Section 5: Background questions}

Please answer the following questions on your background. Thank you very much for your participation!
1. Which clinic are you receiving treatment in?
a. Breast
b. Prostate
c. Lung
d. Thyroid
e. Other

2. What stage of your journey are you currently at?
a. Pre-treatment
b. Treatment
c. Follow-up

3. Age
a. $18-34$
b. $35-49$
c. $50-74$
d. $75+$
e. Rather not say

4. Sex
a. Male
b. Female
c. Other
d. Rather not say

5. Ethnicity
a. Canadian
b. European Canadian
c. African Canadian
d. Asian Canadian
e. First Nations
f. Other
g. Rather not say

6. Highest level of education
a. High school or less
b. Some post-secondary training (i.e., trade, college, university)
c. Completed trade/college diploma
d. Completed university degree
e. Completed post-graduate university degree (e.g., MA, MSc, PhD)
f. Rather not say

7. Household income $(\$)$ 

a. $<40,000 /$ year
b. $40,000-60,000 /$ year
c. $60,000-80,000 /$ year
d. $80,000-100,000 /$ year
e. $>100,000+$ /year
f. Rather not say

ON, Canada. ${ }^{3}$ Department of Biostatistics, Princess Margaret Cancer Centre, Toronto, ON, Canada. ${ }^{4}$ Department of Medicine, University Health Network, Toronto, ON, Canada. ${ }^{5}$ Department of Anaesthesia, University Health Network, Toronto, ON, Canada. ${ }^{6}$ Institute of Health Policy, Management and Evaluation, University of Toronto, Toronto, ON, Canada. ${ }^{7}$ University Health Network Digital, Toronto, ON, Canada. ${ }^{8}$ Department of Bioethics, University Health Network, Toronto, ON, Canada. ${ }^{9}$ Joint Centre for Bioethics, University of Toronto, Toronto, ON, Canada. ${ }^{10}$ Princess Margaret Cancer Centre, Department of Radiation Oncology, 700 University Avenue, Toronto, ON M5G 2M9, Canada.

Received: 3 September 2020 Accepted: 4 March 2021

Published online: 24 March 2021

\section{Abbreviations}

Al: Artificial intelligence; PHI: Personal health information; CRC: Clinical research coordinator; REB: Research Ethics Board; UHN: University Health Network.

\section{Supplementary Information}

The online version contains supplementary material available at https://doi. org/10.1186/s12910-021-00598-3.

Additional file 1. Supplementary Table 1. Results of Q7-17 collapsed into 3 levels. Supplementary Table 2 . Responses categorized by individual clinic, treatment stage, and gender.

\section{Acknowledgements}

The authors would like to acknowledge the valuable contributions of our Clinical Research Coordinators including Maria Braganza, Lea Dungao, Mahesh Kajil, Bernadeth Lao, and Joseph Nachman, as well as all patients who took part in this study.

\section{Authors' contributions}

FFL conceived of the study, and made substantial contributions to the study design, analysis and interpretation of data, and drafting/revising the manuscript. ST, IV, AH, DW, CV and RW made substantial contributions to the study design, analysis and interpretation of data, and drafting/revising the manuscript. KL made substantial contributions to the analysis and interpretation of data, and drafting/revising the manuscript. FH and PM provided substantive revisions to the manuscript. All authors read and approved the final manuscript.

\section{Funding}

This study was not externally funded.

\section{Availability of data and materials}

The datasets used and/or analyzed during the current study are available from the corresponding author on reasonable request.

\section{Ethics approval and consent to participate}

The Research Ethics Board (REB) of the University Health Network (UHN) provided full ethics approval of this study. All participants provided verbal consent to participate prior to completion of the survey. The UHN REB approved the procedure for verbal consent, as participants were provided with a detailed Study Information Letter, and completed the survey in the presence of the Clinical Research Coordinator (CRC). The CRC documented consent for each participant in the study's Participant List (stored separately from survey responses).

\section{Consent for publication}

Not applicable.

\section{Competing interests}

The authors declare that they have no competing interests.

\section{Author details}

${ }^{1}$ Radiation Medicine Program, Princess Margaret Cancer Centre, Toronto, ON, Canada. ${ }^{2}$ Department of Radiation Oncology, University of Toronto, Toronto,

\section{References}

1. Wakabayashi D. Google and the University of Chicago are sued over data sharing. New York Times 2019; https://www.nytimes.com/2019/06/26/

2. Schencker L. How much is too much to tell Google? Privacy lawsuit allenges $U$. of C. Medical Center went too far when sharing patient data. Chicago Tribune 2019; https://www.chicagotribune.com/business/ct-bizlawsuit-university-of-chicago-google-patient-records-20190627-4vnmv fdnv5gcdl5fakgp5zwtna-story.html.

3. Kulynych J, Greely HT. Clinical genomics, big data, and electronic medical records: reconciling patient rights with research when privacy and science collide. J Law Biosci. 2017;4(1):94-132.

4. Caulfield T, Murdoch B. Genes, cells, and biobanks: yes, there's still a consent problem. PLoS Biol. 2017;15(7):e2002654-e2002654.

5. Greely HT. To the Barricades! Am J Bioeth. 2010;10(9):1-2.

6. Ioannidis JP. Informed consent, big data, and the oxymoron of research that is not research. Am J Bioeth. 2013;13(4):40-2.

7. Abouelmehdi K, Beni-Hessane A, Khaloufi H. Big healthcare data: preserving security and privacy. J Big Data. 2018;5(1):1.

8. Nair $\mathrm{K}$, et al. Patients' consent preferences regarding the use of their health information for research purposes: a qualitative study. J Health Serv Res Policy. 2004;9(1):22-7.

9. Willison DJ, et al. Patients' consent preferences for research uses of (Clin Res Ed). 2003;326(7385):373-373.

10. Racine E, Boehlen W, Sample M. Healthcare uses of artificial intelligence: challenges and opportunities for growth. Healthc Manag Forum. 2019;32(5):272-5.

11. Damschroder $L$, et al. Patients, privacy and trust: patients' willingness to allow researchers to access their medical records. Soc Sci Med. 2007:64(1):223-35.

12. The Nuremberg Code (1947). BMJ (Clin Res Ed) 1996; 313(7070):1448.

13. Declaration of Helsinki (1964). BMJ (Clin Res Ed) 1996; 313(7070):1448-9.

14. Balthazar $P$, et al. Protecting your patients' interests in the era of Big Data, artificial intelligence, and predictive analytics. J Am Coll Radiol. 2018;15(3):580-6.

15. Willison DJ, et al. Alternatives to project-specific consent for access to personal information for health research: insights from a public dialogue. BMC Med Ethics. 2008;9(1):18.

16. Jagsi $R$, et al. Effect of public deliberation on patient attitudes regarding consent and data use in a learning health care system for oncology. J Clin Oncol. 2019;37(34):3203-11.

17. Kim KK, Joseph JG, Ohno-Machado L. Comparison of consumers' views on electronic data sharing for healthcare and research. J Am Med Inform Assoc. 2015;22(4):821-30

18. Patil $\mathrm{S}$, et al. Public preferences for electronic health data storage, access, and sharing - evidence from a pan-European survey. J Am Med Inform Assoc. 2016;23(6):1096-106.

19. Joly Y, et al. Fair shares and sharing fairly: a survey of public views on open science, informed consent and participatory research in biobanking. PLoS ONE. 2015;10(7):e0129893-e0129893.

20. Page SA, Manhas KP, Muruve DA. A survey of patient perspectives on the research use of health information and biospecimens. BMC Med Ethics. 2016;17(1):48.

21. Simon CM, et al. Active choice but not too active: public perspectives on biobank consent models. Genet Med. 2011;13(9):821-31. technology/google-university-chicago-data-sharing-lawsuit.html. information in electronic medical records: interview and survey data. BMJ 
22. Caulfield T, Rachul C, Nelson E. Biobanking, consent, and control: a survey of albertans on key research ethics issues. Biopreserv Biobank. 2012;10(5):433-8.

23. Master $Z$, et al. Cancer patient perceptions on the ethical and legal issues related to biobanking. BMC Med Genomics. 2013;6:8.

24. Garrison NA, et al. A systematic literature review of individuals' perspectives on broad consent and data sharing in the United States. Genet Med. 2016;18(7):663-71.

25. Cho MK, et al. Attitudes toward risk and informed consent for research on medical practices: a cross-sectional survey. Ann Intern Med. 2015;162(10):690-6.

26. Tabor HK, et al. Genomics really gets personal: how exome and whole genome sequencing challenge the ethical framework of human genetics research. Am J Med Genet A. 2011;155A(12):2916-24.

27. Twenge JM, Campbell WK, Carter NT. Declines in trust in others and confidence in institutions among American adults and late adolescents, 1972-2012. Psychol Sci. 2014;25(10):1914-23.

28. Robinson RV, Jackson EF. Is trust in others declining in America? An ageperiod-cohort analysis. Soc Sci Res. 2001;30(1):117-45.

29. Jagsi $R$, et al. Perspectives of patients with cancer on the ethics of rapidlearning health systems. J Clin Oncol. 2017;35(20):2315-23.

30. Domaradzki J, Pawlikowski J. Public attitudes toward biobanking of human biological material for research purposes: a literature review. Int J Environ Res Public Health. 2019;16(12):2209.

31. Participate in Research. 2020; https://www.baycrest.org/Baycrest-Pages/ Get-Involved/Participate-in-Research\#: :text=Those\%20who\%20do\%20 not\%20wish,2900.

32. Yip S, et al. "As long as you ask": a qualitative study of biobanking consent—oncology patients' and health care professionals'attitudes, motivations, and experiences - the B-PPAE Study. Oncologist. 2019;24(6):844-56.

33. Jones $\mathrm{RD}$, et al. Patient perspectives on the ethical implementation of a rapid learning system for oncology care. J Oncol Pract. 2017;13(3):e163-75.

34. Caine K, Hanania R. Patients want granular privacy control over health information in electronic medical records. J Am Med Inform Assoc. 2012;20(1):7-15.

35. Bell EA, Ohno-Machado L, Grando MA. Sharing my health data: a survey of data sharing preferences of healthy individuals. AMIA Annu Symp Proc. 2014;2014:1699-708.

36. Kim J, et al. Patient perspectives about decisions to share medical data and biospecimens for research. JAMA Netw Open. 2019;2(8):e199550-e199550.

37. Fradgley EA, et al. Patients' experiences and preferences for opt-in models and health professional involvement in biobanking consent: a crosssectional survey of Australian cancer outpatients. Asia Pac J Clin Oncol. 2019;15(1):31-7.

38. Fradgley EA, et al. Enlisting the willing: a study of healthcare professionalinitiated and opt-in biobanking consent reveals improvement opportunities throughout the registration process. Eur J Cancer. 2018;89:36-41.

39. Kaye J, et al. Dynamic consent: a patient interface for twenty-first century research networks. Eur J Hum Genet. 2015;23(2):141-6.

\section{Publisher's Note}

Springer Nature remains neutral with regard to jurisdictional claims in published maps and institutional affiliations.
Ready to submit your research? Choose BMC and benefit from:

- fast, convenient online submission

- thorough peer review by experienced researchers in your field

- rapid publication on acceptance

- support for research data, including large and complex data types

- gold Open Access which fosters wider collaboration and increased citations

- maximum visibility for your research: over $100 \mathrm{M}$ website views per year

At $\mathrm{BMC}$, research is always in progress.

Learn more biomedcentral.com/submissions 